Jap. J. M. Sc. \& Biol., 13, 77-90, 1960

\title{
AN EVALUATION OF SHIGELLA VACCINES BY HEMAGGLUTINATION ON HUMAN SERA FROM VACCINATED VOLUNTEERS
}

\author{
CHIAKI YAMADA \\ Department of Bacteriology, National Institute of Health, Tokyo
}

(Received: May 7th, 1960)

The bacterial agglutination test has been conventionally employed for the titration of humoral antibodies for Shigella in human sera. In the field trials and also in the small scale trials for evaluating the prophylactic powers of Shigella vaccines, the determination of the degree of increase in bacterial agglutinins following vaccination has been considered as one of the important criteria as well as the survey of the morbidity rates among vaccinated population (Cooper and Keller, 1948; Ando et al., 1958). By means of bacterial agglutination test, it is, however, generally impossible to detect the antibodies for Shigella sonnei in sera from the human subjects immunized with Shigella vaccines or from bacillary dysentery patients if any, whereas it is possible for Shigella flexneri to a considerable extent (Cooper and Keller, 1948; Cooper et al., 1948, 1949a, 1949b; Takigami and Tadokoro, 1953; Ando et al., 1958). It has, therefore, been difficult to evaluate the vaccine prepared from Shigella sonnei by the conventional bacterial agglutination test.

On the other hand, it was established by many workers that bacterial hemagglutination test is generally more sensitive than the bacterial agglutination test (Neter, 1956). In the case of Shigella, Neter and Gorzynski (1954) and Neter and Walker (1954) established the method to determine the agglutinin titers for Shigella by the bacterial hemagglutination test. They carried out with success the surveys of the distribution of hemagglutinin titers for Shigella among some population, using as antigens the erythrocytes modified with soluble antigenic components liberated in the supernatant from bacterial suspensions heated at $100^{\circ} \mathrm{C}$ for 1 hour. Chun and Park (1956) and Chun et al. (1957) reported the studies on the hemagglutination reactions of the rabbit antisera immunized with Shigella flexneri, by employing the tannic acid-treated erythrocytes sensitized with acidextracted antigens as well as the erythrocytes sensitized according to Neter and Gorzynski (1954) or Neter and Walker (1954). Nakaya (1957) studied the relationships among the bacterial agglutinins, the hemagglutinins, and the passive mouse-protective powers of human and rabbit antisera for Shigella, resulting in that the highest sensitivity could be obtained by the hemagglutination test for determination of antibody titers.

In the present experiments, titrations of agglutinins were performed on sera from volunteers immunized with Shigella vaccines and from dysentery patients, by employing the method of hemagglutination test described by the Gastroenteritis Studies Group of the Bacteriology Department at Walter Reed Army Institute of Research (Young, 1959). The present study aimed at the evaluation of the prophylactic powers of Shigella vaccines

山田千昌（国立予防衛生研究所細菌部） 
prepared by chrome alum treatment, with respect to their immunogenicity to human subjects.

This has been accomplished by comparing the hemagglutinin titers of sera from vaccinated individuals with those from individuals recently convalescent from bacillary dysentery. In addition to this, sensitivity and specificity of hemagglutination have been compared with those of bacterial agglutination by using sera from vaccinated human subjects and hyper-immune rabbit sera. It will be presented that the hemagglutination test was very satisfactory at any respect in determination of agglutinin titers for Shigella, particularly in the case for Shigella sonnei.

\section{MATERIALS AND METHODS}

Bacterial strains: S. flexneri 2a, 1675 (abbreviated as $2 a$, hereafter), S. flexnen $2 \mathrm{~b}, \mathrm{P} . \mathrm{R}$. $10307 \mathrm{~B}(2 b)$, S. flexneri 3, 102349 (3) and S. sonnei, r-10 (S) were used in most of experiments and the prototype strains of Shigella were also used in the tests with rabbit antisera.

Sera: (a) Sera from dysentery patients. These were kindly supplied to the authors from the Department of Pediatrics, Jikei-Kai Medical School, Tokyo, Tachikawa Hospital, Tachikawa, and Toyotama Hospital for Infectious Diseases, Tokyo. A pair of serum specimens was obtained from each patient, by the 6th day from onset of illness for the first sample and at later than the 7th day for the convalescent sample. The stool cultures had been positive for some member of Shigella group of bacteria in all cases. The total number of pairs of sera tested was 18; among these 10 from patients caused by S. flexneri $2 \mathrm{a}, 2$ by $S$. flexneri $2 \mathrm{~b}, 3$ by $S$. flexneri 3 and 3 by $S$. sonnei.

(b) Sera from volunteers immunized with Shigella vaccine. In order to determine the prophylactic effects of Shigella vaccine, field trial experiments were performed in 1958 and in 1959 at Camp Katsuta of the Ground Self-Defence Forces. The volunteers for immunization were divided into two randomized groups, one being injected with Flexner-vaccine and the other with Sonnevaccine. They were young male adults, about 20 years of age. The sera tested in the present study were obtained from individuals randomly selected from both vaccinated groups before and after immunization. The vaccines were made by Dr. Ichiro Tadokoro and his coworkers at the Institute for Infectious Diseases, the University of Tokyo, by chrome alum treatment (Ando et al., 1958).

One of the vaccines employed in the 1958 trial was a trivalent Flexner-vaccine prepared from S. flexneri $2 \mathrm{a}, 2 \mathrm{~b}$ and 3 which had a nitrogen content of $58 \mu \mathrm{g} / \mathrm{cc}$ (abbreviated as F-58 vaccine hereafter). The other one was a monovalent Sonne-vaccine prepared from $S$. sonnei which had a nitrogen content of $33 \mu \mathrm{g} / \mathrm{cc}$ (S-58 vaccine). In this trial each individual was injected 3 successive intracutaneous doses of vaccines in the amount of $0.1 \mathrm{cc}$ at intervals of 1 week. Blood was collected from each subject immediately before injecting the first dose of vaccine on April 25th of 1958 and 2 months after injecting the third dose of vaccine on July 14th of 1958 . It should be of importance to mention here that there occurred an outbreak of dysentery epidemic by $S$. sonnei among the persons in the Camp in the middle of May in 1958, that was approximately 1 month after the third injections of the vaccination course. According to the survey records on this outbreak, it was clearly shown that, as far as the Sonne-vaccine employed at that time is concerned, it revealed no significant prophylactic powers against the infection by $S$. sonnei for the individuals vaccinated with S-58 vaccine. Additionally, it cannot be denied that this event made the assessment of the results of the agglutinin determination for $S$. sonnei on the sera from the individuals closely exposed to the epidemic somewhat invalid, irrespective of whether they were obtained from individuals recovered from illness or from apparently healthy individuals in that outbreak. This point will be emphasized at the later part of the present report.

The vaccines used in the 1959 trial were a divalent Flexner-vaccine containing organisms of $S$. flexner $2 \mathrm{~b}$ and 3 and a monovalent Sonne-vaccine, with nitrogen contents of $43 \mu \mathrm{g} / \mathrm{cc}$ and $40 \mu \mathrm{g} / \mathrm{cc}$, respectively (abbreviated as F-59 vaccine and S-59 vaccine, respectively). The immunization course was precisely the same as in the 1958 trial, except the amount of the first shot, where $0.05 \mathrm{cc}$ was injected instead of $0.1 \mathrm{cc}$. Blood was collected in this trial from each subject immediately before injecting the first dose of vaccine on April 7th to 9th of 1959 and 3 weeks after injecting the third dose of vaccine on May 13th of 1959.

The number of pairs of sera were as follows : 28 pairs from individuals immunized with F-58 
vaccine in the 1958 trial; 28 from those with S-58 vaccine in the 1958 trial; 18 from those with F-59 vaccine in the 1959 trial; and 17 from those with S-59 vaccine in the 1959 trial. The individuals mentioned above received Shigella vaccine for the first time. Besides those, 52 individuals whose sera were included in the serum specimens in 1959 were immunized with either vaccine not only in 1958, but also in 1959. Among them, 14 individuals were given Flexner-vaccine alone and 12 Sonne-vaccine alone in both year, whereas the other 26 were given alternatively in each year.

(c) Hyper-immune rabbit antisera to S. flexneri and S. sonnei. Rabbit antisera were prepared against formalinized cultures of the prototype strains of $S$. flexneri and $S$. sonnei, by the method of Edwards and Ewing (1955). The absorbed factor sera to $S$. flexneri were also prepared according to their method.

All of the serum specimens were stored at $4{ }^{\circ} \mathrm{C}$ and heated at $56^{\circ} \mathrm{C}$ for 30 minutes immediately before use.

Tris (hydroxymethyl)-aminomethane buffered saline (TBS): The composition of buffered saline used in hemagglutination and bacterial agglutination as diluent were $\mathrm{NaCl}, 7.5 \mathrm{~g} ; \mathrm{MgCl}_{2} \cdot 6 \mathrm{H}_{2} \mathrm{O}$, $0.1 \mathrm{~g} ; \mathrm{CaCl}_{2} \cdot 2 \mathrm{H}_{2} \mathrm{O}, 0.02 \mathrm{~g}$; tris (hydroxymethyl)-aminomethane (L. Light \& Co., Ltd., England), $6.05 \mathrm{~g} ; 0.2 \mathrm{M} \mathrm{HCl}, 210 \mathrm{cc}$. in $1,000 \mathrm{cc}$.

Bacterial agglutination test (BA test): The overnight growth at $37^{\circ} \mathrm{C}$ on nutrient agar was suspended at a concentration of $10^{9}$ organisms per cc in physiological saline containing $0.3 \%$ formalin. Agglutination reactions were read after addition of $0.2 \mathrm{cc}$ of bacterial suspensions to each tube containing $0.2 \mathrm{cc}$ of serial two-fold serum dilutions followed by placing the reaction tubes in a $50^{\circ} \mathrm{C}$ water bath for 18 hours.

Hemagglutination test (HA test) : HA test was performed according to the methods described by the Gastroenteritis Studies Group of the Bacteriology Department at Walter Reed Army Institute of Research (Young, 1959). The outline of this method is as follows.

(a) Preparation of polysaccharide antigen. An equal quantity of $0.1 \mathrm{~N} \mathrm{NaOH}$ was added to the $35 \mathrm{cc}$ bacterial suspension prepared from the growth on 15 agar plates. After the mixture was heated under flowing steam for 70 minutes at $100^{\circ} \mathrm{C}$, it was cooled and adjusted to $\mathrm{pH} 7.0$ with $1 \mathrm{~N} \mathrm{HCl}$, followed by dialysis in the cold against distilled water for 24 hours changing water several times. Then, it was centrifuged at $8,000 \mathrm{rpm}$ for 30 minutes and the suspernatant was filtered through a Seitz filter. The filtrate was preserved in a refrigerator and used as polysaccharide antigen. No decrease of antigenicity of the filtrate was recognized during the experimental period of 3 months. The media used for the bacterial growth contained yeast extract (Oriental Kobo Co., Ltd., Tokyo), $5 \mathrm{~g}$; peptone, $15 \mathrm{~g}$; phytone (Baltimore Biological Laboratory, Baltimore), $5 \mathrm{~g} ; \mathrm{NaCl}$, $14 \mathrm{~g}$; Agar (Nihon-Eiyo Kagaku Co., Ltd., Tokyo), $14 \mathrm{~g}$; glycerol, $50 \mathrm{cc}$; casein hydrolysate $50 \mathrm{cc}$ in $1,000 \mathrm{cc}$ After sterilization at $121^{\circ} \mathrm{C}$ for 15 minutes, pour plates were made in Petri dishes of $100 \mathrm{~mm}$ in diameter. The plates inoculated heavily with overnight slant cultures were incubated in a jar containing $5 \%$ carbon dioxide at $37^{\circ} \mathrm{C}$ for 18 to 24 hours. The bacteria on those plates were used for antigen extraction as mentioned above.

(b) Standardization of polysaccharide antigen. Human $\mathrm{O} \mathrm{Rh}$ negative red blood cells were purchased from a blood bank, that had been preserved by an addition of equal amounts of Alsever's solution. The red blood cells were washed immediately before use 3 times with 3 volumes of TBS centrifuging each time for 3 minutes at $1,800 \mathrm{rpm}$. TBS was added to the packed cells to make a $10 \%$ suspension ( $10 \% \mathrm{NHE}$ ). This suspension was used for antigen sensitization of red blood cells. The suspension was further diluted to $1 \%$ for the normal human erythrocyte control ( $1 \%$ NHE). The polysaccharide antigen was diluted to $1: 5,1: 10,1: 20$ and $1: 40$ in TBS. One half cc quantities of $10 \% \mathrm{NHE}$ were added to $0.5 \mathrm{cc}$ of each of the antigen dilutions. After thorough shaking, the tubes were incubated in a water bath at $37^{\circ} \mathrm{C}$ for 2 hours with occasional shakings, followed by washing 3 times with TBS. The resulting antigen sensitized human erythrocytes were brought to $5.0 \mathrm{cc}$ with TBS so as to make a $1 \%$ suspension (ASHE). A serial two-fold dilution of hyper-immune rabbit antiserum homologous to the ansigen under test was made from a dilution of $1: 40$ to $1: 10,240$. After addition of $0.2 \mathrm{cc}$ of $1 \%$ ASHE to $0.2 \mathrm{cc}$ of each of the serum dilutions, the tubes were incubated in a water bath at $37^{\circ} \mathrm{C}$ for 2 hours until the agglutination was observed. As control tubes, the mixture of serum with $1 \% \mathrm{NHE}$, that of TBS with $1 \%$ ASHE and that of TBS with $1 \%$ NHE were always set in the test series. The most suitable dilution of the antigen which gave nearly the highest titer in the above standardization tests was employed for performance of the HA tests on sera tested in the present study.

(c) Performance of the HA test. Serial two-fold dilutions of previously inactivated test sera were prepared from $1: 5$ to $1: 320$ in quantities of $0.2 \mathrm{cc}$, to which equal volumes of $1 \%$ ASHE 
were added. In the cases of sera from dysentery patients, higher dilutions were also made. The tubes were shaken and incubated in a water bath at $37^{\circ} \mathrm{C}$ for 2 hours. Agglutination was read by examination of the pattern of settling of the erythrocytes on the bottom of the tube. The similar control mixtures as in the standardization of antigen were also set up.

Definition of agglutinin titer: Since dilution of the test sera started from $1: 5$, to which were added the same quantities of antigen, the dilution can be expressed in a form of $1:\left(5 \times 2^{n}\right)$, where $n$ is the number of dilution test tubes. The agglutinin titers in the experimental results are indicated by $n$ and the increase and the decrease in titers are expressed by the difference between values of $n$. Accordingly, the titers of the sera before and after vaccination in the 1958 trial and those in the 1959 trial were designated as $n_{0}, n_{1}, n_{2}$ and $n_{3}$, respectively.

\section{RESULTS}

\section{Agglutinin Titers of Volunteers Vaccinated with Shigella Vaccine}

To determine the level of antibody titers for Shigella in sera from normal healthy human subjects, titrations of hemagglutinins and bacterial agglutinins were simultaneously performed on sera from volunteers prior to vaccination with Shigella vaccines. The individual serum obtained from 56 volunteers before vaccination in the 1958 trial was tested for their agglutinin titers for $S$. flexneri $2 \mathrm{a}, 2 \mathrm{~b}, 3$ and $S$. sonnei by $\mathrm{HA}$ and BA tests. In the 1959 trial, 18 sera were tested for their hemagglutinin titers for $S$. flexneri $2 \mathrm{a}$ and 3 which were the homologous types of Shigella contained in F-59 vaccine, and 17 sera for $S$. sonnei, the homologous type in S-59 vaccine to be given. The frequency distributions of titers are shown in Table 1 . It can be seen that no detectable amount of agglutinin were found in 20 to $35 \%$ of sera, although a few showed a considerably high titers. The mean hemagglutination titers of individuals in these groups were 1.0 to 2.9 . This fact seems to indicate that normal healthy adults had antibodies for Shigella in their sera, though in a lower degree. The other point to be emphasized here is that out of 56 sera in the 1958 trial tested for bacterial agglutinins for S. sonnei only one was found positive, while by HA test 40 sera among them reacted positively with titers of 1 dilution tube or higher. The mean titer in the latter case was 1.7, which can be considered to be in a equivalent level of agglutinin content for $S$. flexneri. This fact clearly supports the higher sensitivity in HA test than that in BA test for detection of antibodies.

In Table 2 are shown the titers 2 months after vaccination with F-58 vaccine, which indicate that mean hemaggultinin titers were approximately 4 not only for 3 homologous antigens, but also for $S$. sonne $i$ which was the heterologous type. The same was true in the reverse experimental systems as will be described in the following. Since it is generally believed that $S$. sonne $i$ shares no common antigens with $S$. flexneri, the reason is not clear for the contradiction recognized in the above results and remains for further study. It is also obvious here that the hemagglutinin titers for $S$. sonnei were much higher than the bacterial agglutinin titers, which were practically negative in most of the sera.

The agglutinin titers of those who received S-58 vaccines are listed in Table 3 . The hemagglutinin titers for $S$. sonnei increased to an appreciable extent, which could not be demonstrated by BA test. As stated above, the levels of agglutinin contents for $S$. flexneri, the heterologous types in this case, also shifted towards somewhat higher compared to those before vaccination.

Since the results obtained hitherto indicates evidently that agglutinins for $S$. sonnei can be detected only by HA test but not by BA test in the first place and no significant 
Table 1. Agglutinin titers of sera from volunteers before vaccination with Shigella vaccines

\begin{tabular}{|c|c|c|c|c|c|c|c|c|c|c|c|}
\hline \multirow{4}{*}{$\begin{array}{l}\text { Agglutinin } \\
\text { titer } \\
\left(\boldsymbol{n}_{0}\right)\end{array}$} & \multicolumn{8}{|c|}{ Sera from volunteers in the 1958 trial } & \multirow{2}{*}{\multicolumn{3}{|c|}{$\begin{array}{l}\text { Sera from volunteers } \\
\text { in the } 1959 \text { trial }\end{array}$}} \\
\hline & \multicolumn{8}{|c|}{ Strain } & & & \\
\hline & \multicolumn{2}{|c|}{$2 a$} & \multicolumn{2}{|c|}{$2 b$} & \multicolumn{2}{|c|}{3} & \multicolumn{2}{|c|}{$S$} & $2 b$ & 3 & $S$ \\
\hline & $\mathrm{HA}$ & $\mathrm{BA}$ & $\mathrm{HA}$ & $\mathrm{BA}$ & $\mathrm{HA}$ & $\mathrm{BA}$ & $\mathrm{HA}$ & $\mathrm{BA}$ & $\mathrm{HA}$ & HA & $\mathrm{HA}$ \\
\hline 0 & 11 & 23 & 20 & 18 & 13 & 5 & 16 & 55 & 4 & 4 & 0 \\
\hline 1 & 12 & 12 & 20 & 20 & 13 & 9 & 10 & 0 & 5 & 4 & 0 \\
\hline 2 & 19 & 12 & 11 & 6 & 14 & 12 & 13 & 1 & 4 & 5 & 4 \\
\hline 3 & 10 & 7 & 4 & 9 & 10 & 18 & 11 & 0 & 4 & 4 & 10 \\
\hline 4 & 3 & 1 & 1 & 3 & 4 & 8 & 4 & 0 & 0 & 1 & 3 \\
\hline 5 & 0 & 1 & 0 & 0 & 1 & 3 & 2 & 0 & 0 & 0 & 0 \\
\hline 6 & 1 & 0 & 0 & 0 & 1 & 1 & 0 & 0 & 1 & 0 & 0 \\
\hline $\begin{array}{l}\text { Number of } \\
\text { specimen }\end{array}$ & 56 & 56 & 56 & 56 & 56 & 56 & 56 & 56 & 18 & 18 & 17 \\
\hline$\underset{\left(\overline{\boldsymbol{n}}_{0}\right)}{\operatorname{Mean} \text { titer }}$ & 1.7 & 1.2 & 1.0 & 1.3 & 1.8 & 2.5 & 1.7 & 0.04 & 1.7 & 1.7 & 2.9 \\
\hline
\end{tabular}

Agglutinin titer is defined by $n$ in $5 \times 2^{n}$, which is the reciprocal of serum dilution. $2 a, 2 b, 3$ and $S$ indicate Shigella flexneri $2 \mathrm{a}, 2 \mathrm{~b}, 3$ and Shigella sonnei, respectively, employed as antigen for titration. HA and BA mean hemagglutination and bacterial agglutination, respectively. Figures show the number of serum specimens with the indicated titers.

Table 2. Agglutinin titers of sera from volunteers after vaccination with $F-58$ vaccine

\begin{tabular}{|c|c|c|c|c|c|c|c|c|}
\hline \multirow{3}{*}{$\underset{\left(n_{1}\right)}{\text { Agglutinin titer }}$} & \multicolumn{8}{|c|}{ Strain } \\
\hline & \multicolumn{2}{|c|}{$2 a$} & \multicolumn{2}{|c|}{$2 b$} & \multicolumn{2}{|c|}{$3 a$} & \multicolumn{2}{|c|}{$S$} \\
\hline & $\mathrm{HA}$ & $\mathrm{BA}$ & $\mathrm{HA}$ & $\mathrm{BA}$ & $\mathrm{HA}$ & $\mathrm{BA}$ & $\mathrm{HA}$ & $\mathrm{BA}$ \\
\hline 0 & 1 & 1 & 1 & 1 & 1 & 1 & 1 & 24 \\
\hline 1 & 0 & 3 & 0 & 2 & 0 & 1 & 3 & 0 \\
\hline 2 & 4 & 6 & 3 & 4 & 1 & 0 & 3 & 4 \\
\hline 3 & 10 & 9 & 10 & 10 & 7 & 5 & 3 & 0 \\
\hline 4 & 5 & 5 & 6 & 9 & 8 & 8 & 7 & 0 \\
\hline 5 & 5 & 4 & 3 & 2 & 6 & 6 & 6 & 0 \\
\hline 6 & 2 & 0 & 5 & 0 & 5 & 7 & 3 & 0 \\
\hline 7 & 1 & 0 & 0 & 0 & 0 & 0 & 2 & 0 \\
\hline $\begin{array}{r}\text { Number of } \\
\text { specimen }\end{array}$ & 28 & 28 & 28 & 28 & 28 & 28 & 28 & 28 \\
\hline$\underset{\left(\bar{n}_{0}\right)}{\text { Mean titer }}$ & 3.6 & 2.9 & 3.8 & 3.1 & 4.1 & 4.3 & 3.9 & 0.3 \\
\hline
\end{tabular}

See footnote to Table 1 . 
Table 3. Agglutinin titers of sera from volunteers after vaccination with $S-58$ vaccine

\begin{tabular}{|c|c|c|c|c|c|c|c|c|}
\hline \multirow{3}{*}{$\underset{\left(n_{1}\right)}{\text { Agglutinin titer }}$} & \multicolumn{8}{|c|}{ Strain } \\
\hline & \multicolumn{2}{|c|}{$2 a$} & \multicolumn{2}{|c|}{$2 b$} & \multicolumn{2}{|c|}{3} & \multicolumn{2}{|c|}{$S$} \\
\hline & HA & $\mathrm{BA}$ & $\mathrm{HA}$ & $\mathrm{BA}$ & $\mathrm{HA}$ & $\mathrm{BA}$ & $\mathrm{HA}$ & $\mathrm{BA}$ \\
\hline 0 & 2 & 2 & 1 & 5 & 2 & 0 & 0 & 24 \\
\hline 1 & 0 & 4 & 5 & 3 & 3 & 0 & 0 & 0 \\
\hline 2 & 6 & 9 & 12 & 12 & 6 & 7 & 2 & 4 \\
\hline 3 & 14 & 9 & 4 & 5 & 7 & 8 & 1 & 0 \\
\hline 4 & 4 & 3 & 5 & 3 & 5 & 9 & 9 & 0 \\
\hline 5 & 1 & 0 & 1 & 0 & 3 & 1 & 9 & 0 \\
\hline 6 & 1 & 1 & 0 & 0 & 2 & 3 & 5 & 0 \\
\hline 7 & 1 & 0 & 0 & 0 & 0 & 0 & 2 & 0 \\
\hline $\begin{array}{l}\text { Number of } \\
\text { specimen }\end{array}$ & 28 & 28 & 28 & 28 & 28 & 28 & 28 & 28 \\
\hline$\underset{\left(\bar{n}_{1}\right)}{\operatorname{Mean} \text { titer }}$ & 2.9 & 2.4 & 2.4 & 1.9 & 3.0 & 3.5 & 4.7 & 0.3 \\
\hline
\end{tabular}

See footnote to Table 1.

Table 4. Hemagglutinin titers of sera from volunteers the in 1959 trial

\begin{tabular}{|c|c|c|c|}
\hline \multirow{3}{*}{$\begin{array}{l}\text { Hemagglutinin } \\
\text { titer } \\
\left(\boldsymbol{n}_{3}\right)\end{array}$} & \multirow{2}{*}{\multicolumn{2}{|c|}{$\begin{array}{c}\text { Sera from volunteers vaccinated } \\
\text { with F-59 vaccine } \\
\text { Strain }\end{array}$}} & \multirow{3}{*}{$\begin{array}{l}\text { Sera from volunteers vaccinated } \\
\text { with S-59 vaccine } \\
\text { Strain } \\
S\end{array}$} \\
\hline & & & \\
\hline & $2 b$ & 3 & \\
\hline 0 & 0 & 0 & 0 \\
\hline 1 & 1 & 3 & 0 \\
\hline 2 & 0 & 5 & 0 \\
\hline 3 & 7 & 10 & 0 \\
\hline 4 & 12 & 12 & 9 \\
\hline 5 & 14 & 9 & 16 \\
\hline 6 & 10 & 6 & 14 \\
\hline 7 & 1 & 0 & 3 \\
\hline $\begin{array}{r}\text { Number of } \\
\text { specimen }\end{array}$ & 45 & 45 & 42 \\
\hline $\begin{array}{l}\text { Mean titer } \\
\left(\overline{\boldsymbol{n}}_{3}\right)\end{array}$ & 4.6 & 3.8 & 5.3 \\
\hline
\end{tabular}

See footnote to Table 1.

difference is found between both tests with $S$. flexneri secondly, the results will be presented in the following only by those obtained by HA test. 
The hemagglutinin titers of the individual sera from 45 volunteers immunized with F-59 vaccine and of those from 42 immunized with S-59 vaccine were determined for $S$. flexneri $2 \mathrm{~b}$ and 3 , and for $S$. sonnei, respectively, i.e., for the homologous type of Shigella contained in the vaccine employed. Among these subjects there were the recruits in 1959 and those who had received either one of the vaccines in 1959 trials. As tabulated in Table 4 , the mean titers were $\bar{n}_{3}=4$ for $S$. flexneri 3 and $\bar{n}_{3}=5$ for $S$. flexneri $2 \mathrm{~b}$ and $S$. sonnei, which were approximately at the similar levels as observed in the corresponding cases in the 1958 trial as shown in Tables 2 and 3.

Table 5. The increase in hemagglutin titers of volunteers in the 1958 trial by vaccination

\begin{tabular}{|c|c|c|c|c|c|c|c|c|}
\hline \multirow{3}{*}{$\begin{array}{c}\text { Increase in } \\
\text { hemagglutinin } \\
\text { titer } \\
\left(n_{1}-n_{0}\right)\end{array}$} & \multicolumn{4}{|c|}{$\begin{array}{l}\text { Volunteers vaccinated with } \\
\text { F-58 vaccine }\end{array}$} & \multicolumn{4}{|c|}{$\begin{array}{l}\text { Volunteers vaccinated with } \\
\text { S-58 vaccine }\end{array}$} \\
\hline & \multicolumn{4}{|c|}{ Strain } & \multicolumn{4}{|c|}{ Strain } \\
\hline & $2 a$ & $2 b$ & 3 & $S$ & $2 a$ & $2 b$ & 3 & $S$ \\
\hline-3 & 0 & 0 & 0 & 0 & 1 & 0 & 1 & 0 \\
\hline-2 & 1 & 1 & 1 & 3 & 1 & 0 & 2 & 1 \\
\hline-1 & 0 & 0 & 1 & 1 & 0 & 2 & 3 & 0 \\
\hline 0 & 4 & 2 & 2 & 2 & 7 & 6 & 7 & 1 \\
\hline 1 & 5 & 6 & 6 & 5 & 5 & 7 & 1 & 3 \\
\hline 2 & 14 & 2 & 4 & 5 & 8 & 6 & 4 & 2 \\
\hline 3 & 2 & 11 & 8 & 2 & 3 & 3 & 6 & 6 \\
\hline 4 & 1 & 1 & 3 & 8 & 1 & 3 & 3 & 9 \\
\hline 5 & 0 & 3 & 1 & 0 & 1 & 1 & 1 & 4 \\
\hline 6 & 1 & 2 & 2 & 2 & 1 & 0 & 0 & 2 \\
\hline $\begin{array}{l}\text { Number of pairs } \\
\text { of sera }\end{array}$ & 28 & 28 & 28 & 28 & 28 & 28 & 28 & 28 \\
\hline Mean increase & 1.9 & 2.6 & 2.3 & 2.1 & 1.4 & 1.5 & 1.2 & 3.3 \\
\hline$\%$ of response* & 82 & 89 & 86 & 79 & 68 & 71 & 54 & 93 \\
\hline
\end{tabular}

The increase in hemagglutinin titer $\left(\boldsymbol{n}_{1}-\boldsymbol{n}_{0}\right)$ is obtained by subtracting the titer before vaccination $\left(n_{0}\right)$ from that after immunization $\left(n_{1}\right) . * \%$ of Response indicates the per-centage of the volunteers with increased titer to the total volunteers. See also footnote to Table 1.

In order to demonstrate clearly the antibody response in human subjects to Shigella vaccines employed in the present trials, the increase in hemagglutinin titers were estimated on each individual pair of sera, by subtracting the titer of the serum specimens prior to immunization $\left(n_{0}\right.$ or $\left.n_{2}\right)$ from that following immunization $\left(n_{1}\right.$ or $n_{3}$, respectively). The results are summarized in Tables 5 and 6 , which not only indicate that the increase in the homologous agglutinin titers was in a range from 2 to 3 dilution tubes on average, but also indicate that the increase in the heterologous agglutinin titers was in a range from 1 to 2 dilution tubes, even in a less degree. The results also suggest that no response took place to the immunization of vaccines in a certain number of individuals. The rates of negative response were 10 to $21 \%$ for Flexner-vaccine and 0 to $8 \%$ for Sonne-vaccine. The serum specimens included in Table 6 were picked out of those 
Table 6. The increase in hemagglutinin titers of volunteers in the 1959 trial by vaccination

\begin{tabular}{|c|c|c|c|c|c|c|c|}
\hline \multirow{3}{*}{$\begin{array}{l}\text { Increase in } \\
\underset{\left(n_{3}-n_{2}\right)}{\text { hemagglutinin }} \text { titer }\end{array}$} & \multicolumn{3}{|c|}{$\begin{array}{l}\text { Volunteers vaccinated with } \\
\text { vaccine }\end{array}$} & \multicolumn{4}{|c|}{$\begin{array}{l}\text { Volunteers vaccinated with } \\
\text { vaccine }\end{array}$} \\
\hline & \multicolumn{2}{|c|}{ F-59 } & \multirow{2}{*}{$\frac{\mathrm{S}-59}{S}$} & \multirow{2}{*}{$\frac{\mathrm{F}-58}{2 b}$} & \multirow{2}{*}{$\&$} & \multirow{2}{*}{$\frac{F-59}{3}$} & \multirow{2}{*}{$\begin{array}{c}\mathrm{S}-58 \& \\
\mathrm{~S}-59 \\
S\end{array}$} \\
\hline & $2 b$ & 3 & & & & & \\
\hline 0 & 1 & 0 & 0 & 2 & & 3 & 1 \\
\hline 1 & 0 & 1 & 4 & 11 & & 9 & 5 \\
\hline 2 & 2 & 8 & 4 & 0 & & 1 & 6 \\
\hline 3 & 6 & 4 & 8 & 1 & & 1 & 0 \\
\hline 4 & 6 & 4 & 1 & 0 & & 0 & 0 \\
\hline 5 & 2 & 0 & 0 & 0 & & 0 & 0 \\
\hline 6 & 1 & 1 & 0 & 0 & & 0 & 0 \\
\hline $\begin{array}{l}\text { Number of pairs of } \\
\text { sera }\end{array}$ & 18 & 18 & 17 & 14 & & 14 & 12 \\
\hline Mean increase & 3.4 & 2.8 & 2.4 & 1.0 & & 0.9 & 1.4 \\
\hline$\%$ of response & 90 & 100 & 100 & 86 & & 79 & 92 \\
\hline
\end{tabular}

See footnotes to Tables 1 and 5 .

tabulated in Table 4 and divided into two groups. Namely, one group consisted of sera from the recruits in 1959, the other consisted of those from individuals receiving the same type of vaccine successively in both trials in 1958 and 1959. In the former group the increase in titer appears to be of the same degree as that in 1958, but in the latter group the mean increase in titer was merely 1 dilution tube. This seems to lead to the implication that there existed a certain level of titers which could be attained by injection of the vaccines employed, since the agglutinin titers before injection of F-59 vaccine or of S-59 vaccine remained considerably on a high level, as can be seen in Table 8, but no appreciable increase was observed by the booster immunization.

\section{Agglutinin Titers in Bacillary Dysentery Patients}

For comparison of the agglutinin titers between the individuals vaccinated with Shigella vaccines and patients suffering from bacillary dysentery, a number of pairs of sera of dysentery patients were titrated against the same type of Shigella as isolated from the respective patients by HA test. In Table 7 the distribution of hemagglutinin titers of patients is listed. A pair of sera from each patient consisted of a serum specimen obtained by the 6th day from onset of illness and that obtained later than the 7 th day, i.e., during the convalescent period. Although the number of pairs of sera was much fewer in this case than that of vaccinated individuals, 16 cases out of 18 showed a marked increase in hemagglutinin titers. For example, one of the patients by $S$. sonnei showed a titer of 7 , even on the second day of illness and the other one showed a titer of 9 on the 6th day. On the other hand, only 2 patients of $S$. flexneri $2 a$ gave no increase in hemagglutinin titer during the course of illness, remaining in a titer of 3 on the 11th 
day in one case and on the 17 th day in the other. It would be reasonable to draw a conclusion from the comparison of titers between vaccinated individuals and dysentery patients that the level of the agglutinin titers attained by injection of the vaccines were significantly lower than that acquired after Shigella infection.

Table 7. Hemagglutinin titers of sera from dysentery patients

\begin{tabular}{|c|c|c|c|c|c|c|c|c|}
\hline \multirow{3}{*}{$\begin{array}{l}\text { Hemagglutinin } \\
\text { titers }\end{array}$} & \multicolumn{8}{|c|}{ Antigens and causative types of Shigella } \\
\hline & \multicolumn{2}{|c|}{$2 a$} & \multicolumn{2}{|c|}{$2 b$} & \multicolumn{2}{|c|}{3} & \multicolumn{2}{|c|}{$S$} \\
\hline & Onset & $\begin{array}{c}\text { Covales- } \\
\text { cent }\end{array}$ & Onset & $\begin{array}{c}\text { Covales- } \\
\text { cent }\end{array}$ & Onset & $\begin{array}{c}\text { Covales- } \\
\text { cent }\end{array}$ & Onset & $\begin{array}{c}\text { Oovales- } \\
\text { cent }\end{array}$ \\
\hline 0 & 1 & & & & & & & \\
\hline 1 & 2 & & & & & & & \\
\hline 2 & 4 & & & & & & & \\
\hline 3 & 2 & 2 & 1 & & 1 & & & \\
\hline 4 & 1 & & & & 2 & & & \\
\hline 5 & & 6 & 1 & & & 1 & 1 & \\
\hline 6 & & 1 & & & & 2 & & 1 \\
\hline 7 & & 1 & & & & & 1 & 1 \\
\hline 8 & & & & 2 & & & & \\
\hline 9 & & & & & & & 1 & 1 \\
\hline $\begin{array}{l}\text { Number of } \\
\text { specimens }\end{array}$ & 10 & 10 & 2 & 2 & 3 & 3 & 3 & 3 \\
\hline Mean titer & 2 & 5 & 4 & 8 & 4 & 5.7 & 7 & 7.3 \\
\hline
\end{tabular}

Hemagglutination was performed on pairs of serum specimens which were obtained from dysentery patients each at the onset of illness and at the convalescent period. The same type of Shigella was employed for antigens as isolated from the respective patients.

See also footnote to Table 1.

\section{The Persistence of Agglutinins after Vaccination}

In an attempt to follow up the process of the persistence of the increased agglutinin levels in human subjects after vaccination with Shigella vaccines, the sera obtained from the volunteers who had received a course of 3 injections of $\mathrm{F}-58$ vaccine or of S-58 vaccine approximately one year after the vaccination were tested for their hemagglutinin titers against the homologous type of Shigella. As shown in Table 8, one can recognize that the hemagglutinins were persisting on a fairly high level, that is, in a mean titer of 3 for each antigen tested. For presenting the degree of the decrease in titers clearly, the agglutinin titers of each serum specimen after one year from the immunization $\left(\boldsymbol{n}_{2}\right)$ was subtracted by that of each respective serum specimen taken shortly after vaccination in the 1958 trial $\left(n_{1}\right)$. Table 9 indicates that the mean decrease was of approximately 1 dilution tube and 60 to $70 \%$ of the individuals showed the decrease in titers, whereas the remaining individuals retained practically the same level of agglutinin titers. Thus it can be assumed that the response to vaccination persists over a fairly long pericd. 
Table 8. The hemagglutinin titers of sera from volunteers 1 year after the vaccination in the 1958 trial

\begin{tabular}{|c|c|c|c|}
\hline \multirow{3}{*}{$\begin{array}{l}\text { Hemagglutinin } \\
\text { titer } \\
\left(\boldsymbol{n}_{2}\right)\end{array}$} & \multirow{2}{*}{\multicolumn{2}{|c|}{$\begin{array}{c}\begin{array}{c}\text { Sera from volunteers vaccinated } \\
\text { with F-58 }\end{array} \\
\text { Strain }\end{array}$}} & \multirow{3}{*}{$\begin{array}{c}\text { Sera from volunteers vaccinated } \\
\text { with S-58 }\end{array}$} \\
\hline & & & \\
\hline & $2 b$ & 3 & \\
\hline 0 & 1 & 3 & 1 \\
\hline 1 & 1 & 4 & 1 \\
\hline 2 & 5 & 1 & 2 \\
\hline 3 & 4 & 4 & 9 \\
\hline 4 & 6 & 4 & 4 \\
\hline 5 & 4 & 4 & 3 \\
\hline 6 & 1 & 2 & 1 \\
\hline $\begin{array}{c}\text { Number of } \\
\text { specimens }\end{array}$ & 22 & 22 & 21 \\
\hline$\underset{\left(\bar{n}_{2}\right)}{\text { Mean titer }}$ & 3.5 & 3.1 & 3.1 \\
\hline
\end{tabular}

See footnote to Table 1.

\section{Comparison of HA Test with BA Test in Specificity and Sensitivity by Using Hyper-Immune Rabbit Sera}

The specificity and sensitivity of HA reaction were compared with those of BA reaction by using hyper-immune rabbit sera for Shigella, with an aim to ascertain the validity of the application of HA tests instead of BA tests as in the case of the present study. Since the results obtained here were mostly in good agreement with those of Chun and Park (1956), of Nakaya (1957) and of Havlik et al. (1959) only several respects are briefly mentioned in the following. As far as S. flexneri $2 \mathrm{a}$ and $2 \mathrm{~b}$ are concerned, no significant difference in the specificity and sensitivity was found between the two tests. With $S$. sonnei, HA reaction was specific, without any cross reaction with antisera against $S$. flexneri as well as BA reaction. It was also confirmed that the former was much more sensitive than the latter, as described by Nakaya (1957). With respect to S. flexneri 3, difference in the specificity was recognized between HA test and BA test, that did not agree with the descriptions by Chun and Park (1956). While the specificity of HA reaction with this type of bacteria varied from one strain to the other from which the polysaccharide antigen was prepared, the following fact was always the same irrespective of strains used. Namely, HA reaction in absorbed type specific sera III was negative in a dilution of $1: 80$, whereas BA titer was $1: 160$. However, the titers of unabsorbed sera for $S$. flexneri 3 were not significant in both tests. It appears, therefore, to be reasonable to apply HA test in determination of agglutinin titers of human sera in place of conventional BA test, so far as those types of bacteria mentioned above are used.

Concerning $S$. flexneri var. X, which contains group antigens 7,8 , 9, the antigen prepared from this type showed completely negative results in HA reactions in any type of the hyper-immune rabbit sera against S. flexneri including the homologous serum. 
Conversely, absorbed group serum 7, 8, 9 reacted with the types possessing group antigens $7,8,9$, such as $S$. flexneri $2 \mathrm{~b}$, and 5 , but did not react with $S$. flexneri var. $\mathrm{X}$ in HA test. This result is consistent with that as evidenced by Chun and Part (1956) and Chun et al. (1957), the reason remaining for the future study. Other points recognized as being inconsistent with the results by Chun and Park (1956) and Chun et al. (1957) were that the hemagglutinin titers of absorbed type specific sera V and VI and group serum 6 determined with the antigens containing the homologous antigenic factor(s) were considerably lower than the corresponding bacterial agglutinin titers and that the unabsorbed serum against $S$. flexneri $1 \mathrm{~b}$ employed in this study gave more specific reactions in $\mathrm{HA}$ test than in $\mathrm{BA}$ test.

Table 9. The difference in hemagglutinin titers of volunteers 1 year after the vaccination in the 1958 trial

\begin{tabular}{|c|c|c|c|}
\hline \multirow{3}{*}{$\begin{array}{c}\text { Difference in } \\
\text { titer } \\
\left(n_{2}-n_{1}\right)\end{array}$} & \multirow{2}{*}{\multicolumn{2}{|c|}{$\begin{array}{l}\begin{array}{l}\text { Volunteers vaccinated with } \\
\text { F-58 }\end{array} \\
\text { Strain }\end{array}$}} & \multirow{3}{*}{$\begin{array}{l}\text { Volunteers vaccinated with } \\
\text { S-58 } \\
\text { Strain } \\
S\end{array}$} \\
\hline & & & \\
\hline & $2 b$ & 3 & \\
\hline 1 & 1 & 1 & 0 \\
\hline 0 & 5 & 8 & 7 \\
\hline-1 & 10 & 6 & 9 \\
\hline-2 & 4 & 4 & 3 \\
\hline-3 & 1 & 2 & 1 \\
\hline-4 & 1 & 0 & 1 \\
\hline-5 & 0 & 1 & 0 \\
\hline $\begin{array}{l}\text { Number of } \\
\text { specimen }\end{array}$ & 22 & 22 & 21 \\
\hline Mean difference & -1.1 & -1.1 & -1.0 \\
\hline$\%$ of response & 73 & 59 & 67 \\
\hline
\end{tabular}

See footnote to Tables 1 and 5 .

\section{DISCUSSION}

The results presented in the present study with $S$. sonnei were in agreement with the findings by Neter and Walker (1954) who demonstrated the wide distribution of hemagglutinins for $S$. sonnei in children with diseases other than bacillary dysentery and in healthy human adults and also the considerably significant increase in the hemagglutinin titers for $S$. sonnei during the course of illness in the case of dysentery.

In the present study it was clearly evidenced that the bacterial agglutinins for $S$. sonnei could be detected in vaccinated volunteers neither before nor after vaccination, whereas hemagglutinins could be demonstrated to the same degree as for $S$. flexneri, due to the high sensitivity of $\mathrm{HA}$ test. In the case of dysentery patients caused by $S$. sonne $i$, if the hemagglutinin titers in their sera were high enough, it might be possible to determine the titers by BA test, though generally resulting in very low titers. This discrepancy 
of the sensitivity between $\mathrm{HA}$ and $\mathrm{BA}$ in the case of $S$. sonnei can be explained in two possible ways. On one hand, the relative insensitivity of BA may be assumed to be accounted for by the presence of $\mathrm{K}$ antigen in this organism, such as in Escherichia coli, which would cause 0 inagglutinability. This possibility, however, cannot be supported by any actual evidence, because no $\mathrm{K}$ antigen was demonstrated so far in S. sonnei. On the other hand, it would be more likely that the discrepancy of the sensitivity in both reactions would be acounted for by the differences in the amount of antigens and in the physico-chemical status of their distribution on the bacterial cells with those on mcdified red blood cells. The study is now under way to verify the second assumption and will be reported elsewhere.

Whether there is any discrepancy of the sensitivity between HA and BA reactions appears to depend upon the serotype of strains employed for preparation of antigens. For example, the discrepancy was not observed in the case of $S$. flexneri $2 \mathrm{a}$ and $2 \mathrm{~b}$, but was seen in the case of $S$. flexneri 3 . Since in the latter HA test was negative with the absorbed type specific serum III of rabbit in spite of positive BA test, it would be likely that one might not deal with the same kind of antibodies in the HA and BA tests, in the titrations of hemagglutinins and bacterial agglutinins in sera from human subjects as studied by the present authors. However, the agglutinin titers determined by both methods did not differ significantly in the case of unabsorbed sera of rabbits and human beings, although the sensitivity of $\mathrm{HA}$ test was rather lower than that of BA test with this type of Shigella.

In $S$. Sonnei, particularly, HA test showed strikingly high sensitivity so that it afforded a valuable way for determination of the agglutinin titers for this type of bacteria in sera from normal healthy human subjects, vaccinated individuals and dysentery patients caused by $S$. sonnei. In addition to this, HA test with $S$. sonne $i$ gave relatively specific reaction without significant cross reaction against the other heterologous antisera, It may, therefore, indicate that this method may be useful as an aid for serological diagnosis of dysentery caused by $S$. sonnei, as reported by Havlik et al. (1959).

The reason is not clear yet why the vaccinated individuals with a certain type of Shigella vaccine gave an increase in the heterologous agglutinin titers, however slight degree it may be, when compared with that in the homologous titers, as shown in Table 5. This fact is not due to a common antigen shared by both the groups of Shigella, because no such common antigen has been demonstrated between them. Thus, in the present stage of knowledge, it is reasonable to believe that the increase in the heterologous agglutinins might be explained by non-specific stimuli by vaccination.

In connection to the specificity of HA test, no explanation is given as yet for the following facts. Inagglutinability of the red blood cells modified with the antigen of $S$. flexneri 3 in absorbed type specific serum III; negative HA reaction with the antigen of $S$. flexneri var. $\mathrm{X}$ in all types of antisera against Flexner bacilli; lower sensitivity in HA test with antigens prepared from $S$. flexneri 5, 6, and Flexner bacilli possessing group antigen 6, i.e., S. flexneri $1 \mathrm{~b}, 3$ and $4 \mathrm{~b}$, in absorbed type specific sera V, VI and absorbed group serum 6, respectively, as compared with that in BA test. For the cause of the facts above mentioned one can entertain possibilities that the antibody combining sites or the biding sites on red blood cells of such type of antigens as mentioned above could be destroyed, because of their labile nature against heat or alkali treatment.

Turning to the meaning of antibodies in sera for the prophylaxis of bacillary dysentery, the problem has not yet been settled, although there is no positive indication for support- 
ing the correlation between the antibodies and their prophylactic effectiveness. Furthermore, no clear-cut evidence has been established on the prophylactic power of Shigella vaccine for human beings. As far as the mouse protective power of the antibodies against Shigella is concerned, Nakaya (1957) reported that the agglutinins themselves would be responsible for the protection of mice from the septicemic death, since the passive mouse-protective power of antisera for Shigella was in proportional relation to the titers of HA and BA. Provided the agglutinins in human sera are responsible for prophylaxis to shigellosis if any, the prophylactic power of vaccines can be evaluated by determining the agglutinin following vaccination, in other words, by their immunogenicity to human beings. On this assumption, the immunogenicity of Shigella vaccines can be critisized from the results obtained in the present study. The mean hemagglutinin titers for the homologous antigen after vaccination were at the levels of $1: 80$ to $1: 160$ of serum dilution and the rates of individuals showing titers beyond $1: 160$ in the vaccinated population were 30 to $50 \%$. Even in the individuals receiving the booster vaccination, the hemagglutinin level remained in the same range as that of individuals receiving only one course of vaccination. The facts seem to indicate that the antibody response. of human subjects stimulated by vaccination is restricted to a certain limit, because no improved method for production of Shigella vaccine is available at present in all practical meanings. Now, on one hand, $\mathrm{S}-58$ vaccine was not evidenced to show effectiveness for protection from the disease caused by S. sonnei, in the case of epidemic outbreak of dysentery by $S$. sonnei among the vaccinated volunteers one month after vaccination in the 1958 trial. In addition to this, the agglutinin titers for $S$. sonnei determined in the 1958 trial might not necessarily represent the true response for the vaccination, since the titration of agglutinins of the volunteers was performed on the sera taken one month after the epidemic outbreak. On the other hand, the evidence that the hemagglutinin titers of dysentery patients in convalescent period were generally at least in $1: 160$ of serum dilution or higher appears to be reasonable to draw the conclusion that the antibody level attained by vaccination was too low to protect the human subject from dysentery, provided that the high level of antibody content in sera is responsible for the protection of dysentery.

In any way, it is conceivable that the determination of hemagglutinins possibly provides a concrete ground for the evaluation of Shigella vaccines.

\section{SUMMARY}

The application of bacterial hemagglutination reaction was undertaken to evaluate the prophylactic effectiveness of Shigella vaccines by titrating the agglutinins in sera obtained from vaccinated volunteers subjected to field trials of dysentery vaccination. The hemagglutinin levels of sera obtained from bacillary dysentery patients were determined as well for comparison.

It was clearly evidenced that the agglutinins against Shigella sonnei could be demonstrated in sera from normal human subjects and vaccinated individuals only by hemagglutination tests but not by bacterial agglutination test.

The hemagglutinin titers of sera from normal human subjects ranged from $1: 10$ to $1: 20$ of serum dilutions on average for Shigella flexneri $2 \mathrm{a}, 2 \mathrm{~b}$, and 3 and Shigella sonnei. The hemagglutinin levels attained by vaccination were up to a mean titer of $1: 160$, even by the booster vaccination. The agglutinins persisted for 1 year following vaccination. 
The hemagglutinins in sera from dysentery patients taken during the convalescent period were at least in a titer of $1: 160$ and higher in most cases.

Discussions were made on the prophylactic power of Shigella vaccines from the viewpoint of the hemagglutinin levels, with the conclusion that the antibody level attained by vaccination was too low to protect the human subject from dysentery.

The author's thanks are due to Dr. Chūichi Tanaka, the Department of Pediatrics, Jikei-Kai Medical School, Tokyo, and Dr. Hitoshi Tsurumi, Tachikawa Hospital, Tachikawa, for supplying the serum specimens from bacillary dysentery patients. The author is indebted to Dr. Hideo Fukumi, Chief of the Department of Bacteriology, National Institute of Health, Tokyo, for his direction of the present study and his advice in preparation of this report. The author is also indebted to Dr. Shōgo Kuwabara, professor of the Department of Microbiology, Tōhō Medical School, Tokyo, for his revision of the manuscript. Thanks are due to Drs. Rintarō Nakaya aud Riichi Sakazaki, the Department of Bacteriology, National Institute of Health, Tokyo, for their advice in performance of the study.

\section{REFERENCES}

Ando, K., TAdokoro, I. \& Yamashita, A. (1958): Studies on the dysentery chrome vaccine. Jap. J. Exper. Med., 28, 353-374.

Chun, D. \& PARK, B. (1956): Demonstration of Shigella flexnen antigens by means of hemagglutination test. J. Infect. Dis., 98, 82-87.

ChUN, D., YANG, Y. \& PARK, H. (1957): A study of the tannic acid hemagglutination test with antigenic substance of Shigella flexneri. J. Infect. Dis., 100, 241-248.

COOPER, M. L. \& Keller, H. M. (1948): Studies in dysentery vaccination. II. Humoral antibody content of sera from children convalscent from dysentery. J. Immunol., 58, 357-360.

COOPER, M. L., TePper, J. \& KelleR, H. M. (1948): Studies in dysentery vaccination. IV. Primary vaccination of children with monovalent 'vaccines of Shigella. J. Immunol., 60, 189203.

CoOper, M. L., Tepper, J. \& Keller, H. M. (1949a): Studies in dysentery vaccination. VI. Primary vaccination of children with polyvalent vaccines of Shigella. J. Immunol., 61, 207219.

CoOper, M. L., Tepper, J. \& Keller, H. M. (1949b): Studies in dysentery vaccination. VII. Response of children to booster injections of Shigella vaccines. J. Immunol., 61, 221-227.

EDWARDS, P. R. \& EwING, W. H. (1955): Identification of Enterobacteriaceae. p. 179, Burges Publishing Company, Minnesota.

Havlik, J., KotT, B. \& PotuZnIK, V. (1959): The indirect haemagglutination test in dysentery caused by Shigella sonnei and Shigella flexneri. J. Clin. Path., 12, 440-443.

NAKAYA, R. (1957): Relationship between agglutinative and mouse-protective antibodies of Shigella immune serum. Jap. J. Bact., 12, 35-40 (text in Japanese).

NETER, E. (1956): Bacterial hemagglutination and hemolosis. Bact. Rev., 2O, 166-188.

NETER, E. \& GORZYNSKI, E. A. (1954): Erythrocyte-modifying capacity of Shigella dysenteriae (Shiga) and its polysaccharide component. Proc. Soc. Exper. Biol. \& Med., 85, 503-506.

Neter, E. \& Walker, J. (1954): Hemagglutination test for specific antibodies in dysentery caused by Shigella sonnei. Am. J. Clin. Path., 24, 1424-1429.

TAKIGAMI, T. \& TADOKORO, I. (1953): Agglutination and mouse protective tests on sera from human subjects at the period of onset of and convalescent from bacillary dysentery. J. Jap. Assoc. Infect. Dis., 27, 64-67 (text in Japanese).

YounG, M. V. (1959): Personal communication to Dr. R. Nakaya. Gastroententeritis Studies Group, Bacteriology Department, Walter Reed Army Institute of Research: "A modification of the hemagglutination test for use in the study of Shigellae and Escherichia coli". Typewritten copy, p. 10. 